\title{
GIS for Operative Support
}

\author{
Gunnar Bygdén \\ Olofsfors $A B$ Nordmaling \\ Sweden
}

\section{Introduction}

Geographic Information System (GIS) is often used when planning the cuttings in the forest. Starting with a good geographical map and pre-planned stand marking at the office, the planning person can walk up the borders of the stand with a high precision GPS and mark / correct the stand borders on a forestry GIS map as an overlay. The planning person may also mark areas where special environmental consideration should be made. There could be special valuable trees or ancient remains that should be avoided from machine traffic or cutting. The advantage by doing this as an overlay on the geographical map is that the stand area can be well calculated and used for estimation of the expected volume together with earlier stand information (e.g. stand inventory). In the forestry map indications could also be made where to put landing, alarm coordinates and other needed information for the machine operators.

Unfortunately the planning person often has too little knowledge about forestry machines and expects the machine operators to choose where to go. Preferably the planning person should also make proposals of where to put the major temporary forestry roads, thus where to find the best ground for such roads. The machine operators on the other hand have seldom time for walking around the stand but like to start more or less directly when arriving to the stand. They start often by cutting around where to put the landing and then continue along the borders of the stand. Thus, the machines may enter areas with less good soil bearing capacity without any previous information. Landing may also be placed on less good spots from the stand point of view. The result is severe rutting around the landing area and a number of wheel ruts in the forest. In worst case the machines may get stuck in forest with expensive rescuing operations. And, a disappointed forest owner looking at all the mess in the forest and will not accept to sell the timber to this company any more.

All these problems belong actually to poor soil knowledge of all involved personal. Less good planning, too heavy machines, too much traffic together with bad weather conditions for the soil conditions are factors causing severe disturbance of the forest soils. The aim must be to adapt machines, traffic and planning to actual soil conditions.

\section{Some soil mechanics}

Many people believe that the soil bearing capacity depends on the soil type. Of cause, a peat land is soft and a gravelly soil is strong, but for mineral soils the bearing capacity is 
not so very different regardless of particle size when it is dry. However, it is with moisture content the particle size class differs. A gravelly soil does not change very much with moisture, a silt soil changes drastic behaviour and a clay soil becomes sticky and slippery with increased moisture content. In the forest we have also to consider a humus layer with high elasticity full with roots from trees and ground vegetation (Wästerlund 1989). The roots may have a significant influence on the ground bearing capacity (Fig. 1) and at moist conditions they may contribute as much as $50 \%$ of the ground bearing strength. Normally the shear strength $(\tau)$ of a soil is described as $\tau=c+\sigma \tan \varphi$, which is the cohesion (c) plus load $(\sigma)$ times the friction angle $(\tan \varphi)$ of the soil. Both parameters will change with increasing moisture content. However, the root component $(\mathrm{Sr})$ is missing and therefore it has been suggested to add a root component, such as $\tau=c+\operatorname{\sigma tan} \varphi+\operatorname{Sr}$ for forestry ground (Wästerlund 1990).

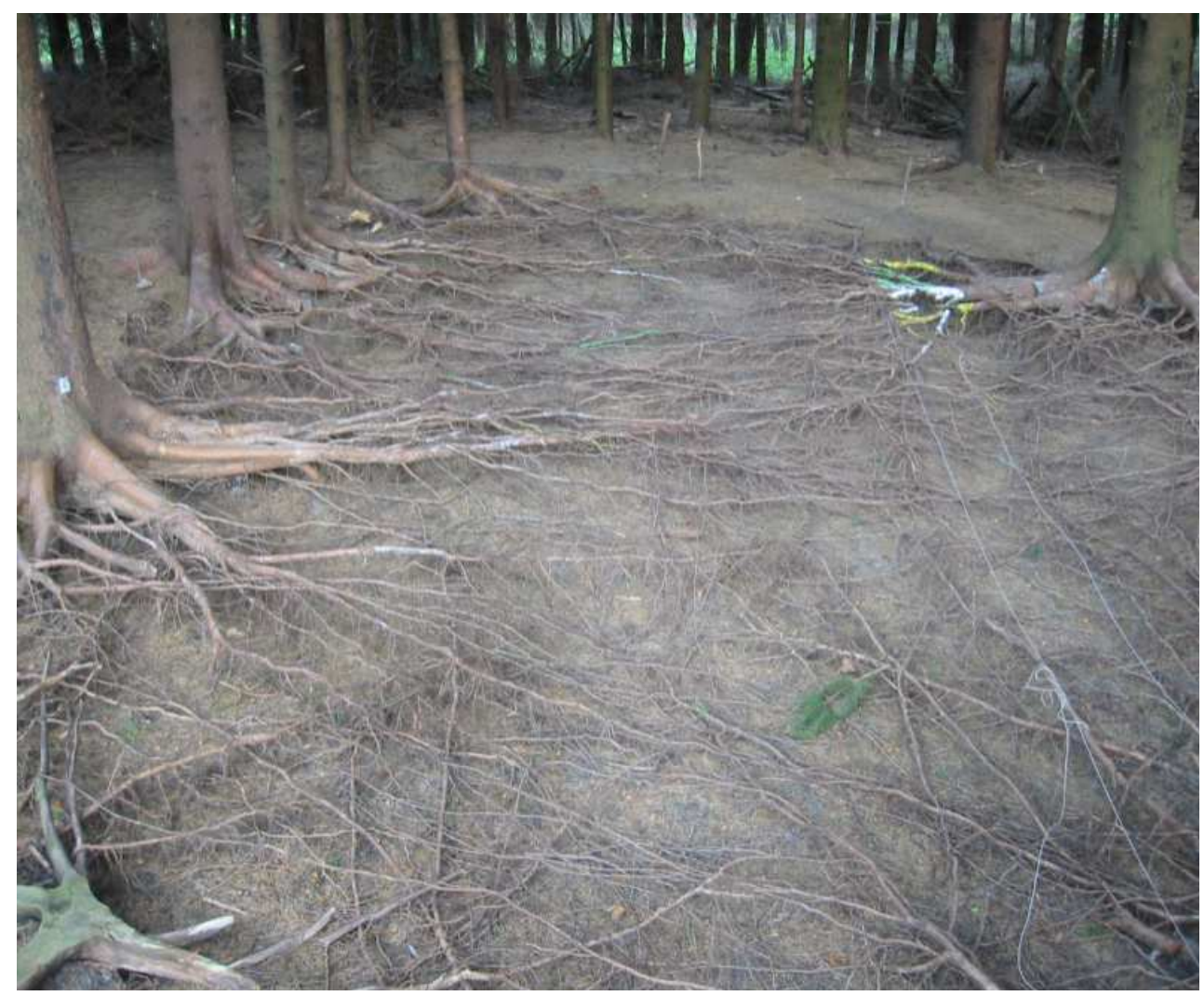

Fig. 1. Surface cover blown away in a spruce stand down to $20 \mathrm{~cm}$ depth showing all the surface roots. A farm tractor has been passing causing root damage. Photo: I. Wästerlund. 
With this important influence of the root armouring of the ground, it becomes clear that deep rutting should be avoided. When the roots are broken, the bearing capacity of a wet ground may decrease to only the half. Furthermore, the rutting of the soil means that the machine is using energy to deform the ground and the wheel ruts are causing the machine to drive uphill seen from the wheel perspective. Thus, the rutting will cause increased fuel consumption and make the operation more expensive.

The bearing capacity of the ground can be measured with a cone penetrometer (Fig. 2). This tool has a cone of $21 \mathrm{~mm}$ in diameter with $30^{\circ}$ angle and is pressed down into the soil with a rate of $3 \mathrm{~cm} / \mathrm{s}$ (WES standard). By checking the ground before passage after a heavy rain, it can be determined if the machine can pass or not or will be making deep wheel ruts. A measured value below $0.3 \mathrm{MPa}$ means that the soil is very soft, between $0.3-0.7 \mathrm{MPa}$ the soil is soft, between 0.7 and 1 the soil is medium hard but may be soft after rain, and above 1 $\mathrm{MPa}$ the soil has a good bearing capacity.

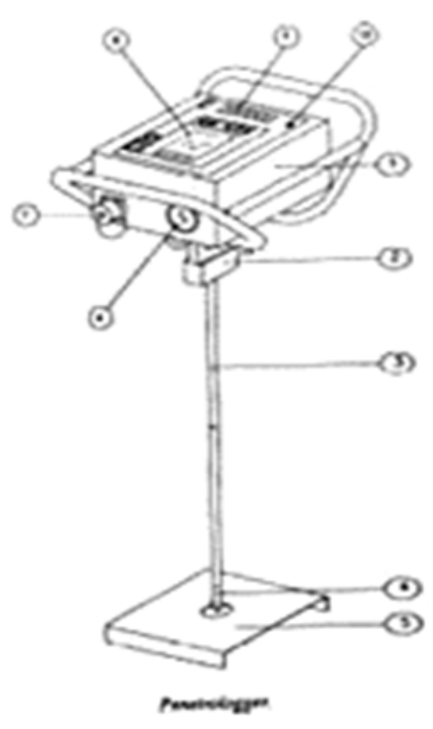

Fig. 2. A registration cone penetrometer.

Andersson (2010) made a study of forest machine rutting in the soil after operation comparing soil strength measured with a cone penetrometer, machine ground pressure and depth of ruts. The soil strength was measured with a cone penetrometer. His conclusion was that on soils below $0.7 \mathrm{MPa}$ severe rutting occurred when the machines ground pressure was above $80 \mathrm{kPa}$ (Fig. 3). 


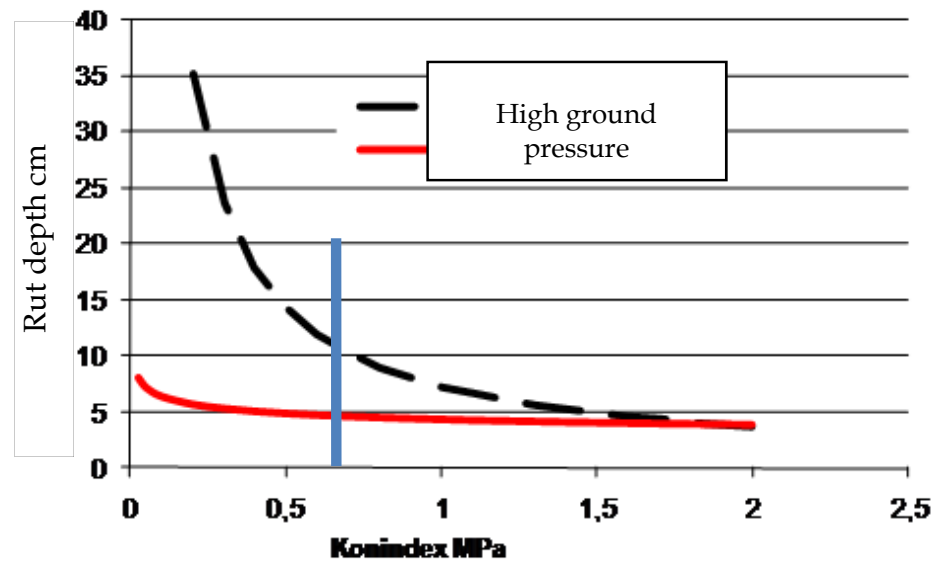

Fig. 3. With high ground pressure and low bearing capacity (below $0.7 \mathrm{MPa}$ ) severe rutting may occur.

Ground pressure in his case was calculated as axle load divided with number of wheels and contact area. The contact area was calculated as wheel radius times the width of tire. It is possible to increase the contact area by increasing the width of the tire, or putting tracks on the wheels. Best effects seem to be with bogey tracks. Bygdén et al. (2003) showed that bogey tracks could both reduce the rutting of the soil and decrease the rolling resistance on soft soils. With bogey tracks the area is calculated as width of the track times the contact length and often the ground pressure is reduced by 30-50\% compared to wheels when using bogey tracks, especially on forwarders. This is important for reduction of rutting on soft soils.

\section{Proposal}

Soil maps are coming slowly into use for forestry operations. Within a few years ahead many national geological institutions will be able to provide soil maps that can be used together with GIS. At least one forest machine manufacturer has started to prepare a system with an integrated soil map to the GIS system. With help of colours soft soils can be marked and guide the machine operators where soft soils can be expected, for instance a red colour could mark soft soils, pink medium soils and yellow colour means normal soils. Thörnewall (2007) introduced a scale from 1 to 5 , where 1 was easy and 5 difficult. He put one scale for soil type, one scale for inclination and one for surface structure and added the numbers. An easy terrain with strong soils could be $1+1+1=3$ and a difficult terrain could be $4+3+2=9$. For road construction he put a price for each number and thereby steering the road construction towards easy terrain. A similar system could also be used for payment for forestry operations, e.g. when soils do have less good bearing capacity, the payment would 
increase as an incitement to use smaller machines or buy proper bogey tracks to reduce the ground pressure and decrease soil disturbance.

Thus, the colour scheme shown in the machine computer should be a warning signal for operator to avoid that area marked with red and be careful when pink colour appears. The planning person must also notice the warning colours and try to avoid operations on those areas or prescribe certain machines or protective measures to be taken such as reducing the ground pressure. The protective measures could be to prescribe use of bogey tracks to the conditions, e.g. aggressive types at snow conditions or types with good supporting construction for soft conditions. A number of different types of wheel and bogey tracks for varying conditions could be supplied through Olofsfors $\mathrm{AB}$.

Both planning personal and operators should work together to calculate the ground pressures of used machines on the district. The calculation must be done per axle of the machine and it is the heaviest axle when loaded that determines the trafficability of the machine. Both categories must be well aware that ground pressures above $80 \mathrm{kPa}$ may cause severe rutting on soils with strength below $0.7 \mathrm{MPa}$ and a heavy rain could reduce the bearing capacity for soils up to $1 \mathrm{MPa}$. Tracks may increase both the trafficability and the stability of many machines by increasing the contact area. The ambition to have machines for forestry operations with ground pressure below $75 \mathrm{kPa}$ will save both the fuel consumption on weak soils and the environment.

\section{Conclusion}

With a soil map as a background in the ordinary site map there will be better possibilities for the operators to avoid rutting and compaction. Route planning will also be better with the knowledge of where the sensitive parts are situated in the logging area. A scaled map with numbers and warning colours should be a useful tool to show less bearing capacity in the logging area.

To measure the machines weight and get exact ground pressure is also a way to minimize soil disturbance.

Decreasing the machine ground pressure with proper bogie tracks should be regular in sensitive areas.

\section{References}

Andersson, E., 2010. Increased harvesting possibilities with suitable ground pressure from harvesting machines. SLU, dept of Forest Resource Management, Umeå. Report No 276.

Bygdén, G., Eliasson, L. \& Wästerlund, I., 2003. Rut depth, soil compaction and rolling resistance when using bogie tracks. J. Terramechanics, 40(3):179-190.

Suvinen, A., 2006. A GIS-based simulation model for terrain tractability. J. Terramechanics 43:427-449.

Thörnewall, D., 2007. Method for use of Geographic Information Systems in long term road planning. SLU, dept of Forest Resource Management, Umeå. Report No 176. 
Wästerlund, I., 1989. Strength components in the forest floor restricting maximum tolerable machine forces. J. Terramechanics, Vol. 26 (2):177-182.

Wästerlund, I., 1990. Soil strength in forestry measured with a new type kind of test-rig. Proc. 10th International Conference of the ISTVS/Kobe, Japan/August 20-24, 1990. Vol. 1:73-82. 


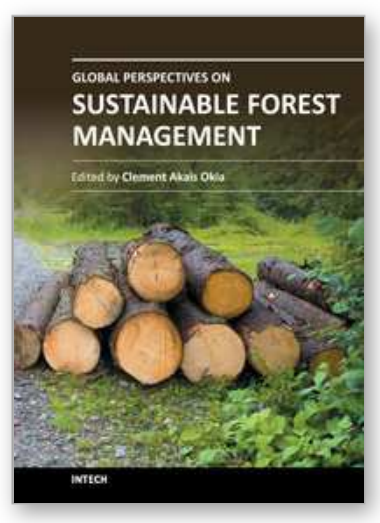

\author{
Global Perspectives on Sustainable Forest Management \\ Edited by Dr. Dr. Clement A. Okia
}

ISBN 978-953-51-0569-5

Hard cover, 300 pages

Publisher InTech

Published online 25, April, 2012

Published in print edition April, 2012

This book is dedicated to global perspectives on sustainable forest management. It focuses on a need to move away from purely protective management of forests to innovative approaches for multiple use and management of forest resources. The book is divided into two sections; the first section, with thirteen chapters deals with the forest management aspects while the second section, with five chapters is dedicated to forest utilization. This book will fill the existing gaps in the knowledge about emerging perspectives on sustainable forest management. It will be an interesting and helpful resource to managers, specialists and students in the field of forestry and natural resources management.

\title{
How to reference
}

In order to correctly reference this scholarly work, feel free to copy and paste the following:

Gunnar Bygdén (2012). GIS for Operative Support, Global Perspectives on Sustainable Forest Management, Dr. Dr. Clement A. Okia (Ed.), ISBN: 978-953-51-0569-5, InTech, Available from:

http://www.intechopen.com/books/global-perspectives-on-sustainable-forest-management/gis-for-operativesupport

\section{INTECH}

open science | open minds

\section{InTech Europe}

University Campus STeP Ri Slavka Krautzeka 83/A 51000 Rijeka, Croatia

Phone: +385 (51) 770447

Fax: +385 (51) 686166 www.intechopen.com

\section{InTech China}

Unit 405, Office Block, Hotel Equatorial Shanghai No.65, Yan An Road (West), Shanghai, 200040, China 中国上海市延安西路65号上海国际贵都大饭店办公楼 405 单元 Phone: +86-21-62489820

Fax: +86-21-62489821 
(C) 2012 The Author(s). Licensee IntechOpen. This is an open access article distributed under the terms of the Creative Commons Attribution 3.0 License, which permits unrestricted use, distribution, and reproduction in any medium, provided the original work is properly cited. 